\title{
On the Solid Solubility Extension by Rapid Quenching and Spinodal Decomposition during Aging in Melt-Spun Cu-Ti Alloys
}

\author{
Shin-ichiro Kondo*, Hiromichi Nakashima and Takao Morimura \\ Department of Materials Science and Engineering, Faculty of Engineering, Nagasaki University, Nagasaki 852-8521, Japan
}

We have examined solid solubility extension for melt-spun $\mathrm{Cu}-\mathrm{Ti}$ alloys $(4,6,7$, and 8 mass\% Ti) in comparison with that for conventional quenched alloys. X-ray diffraction (XRD) measurements revealed that the solid solubility extension for the melt-spun alloys was in the range of 7-8 mass\% Ti, whereas that for quenched alloys was less than 6 mass\% Ti. After annealing the melt-spun alloys at $673 \mathrm{~K}$, the XRD measurements revealed sidebands with no intermetallic compound peaks, bright-field transmission electron microscopy images showed modulated structures, and selected-area diffraction patterns exhibited satellite structures; taken together, these experimental results confirm the occurrence of spinodal decomposition. In this study, however, distinct superlattice reflections were not observed. [doi:10.2320/matertrans.M2018255]

(Received August 1, 2018; Accepted November 20, 2018; Published January 25, 2019)

Keywords: melt-spun, sideband, Cu-Ti alloy, spinodal decomposition, solid solubility extension

\section{Introduction}

Dilute $\mathrm{Cu}-\mathrm{Ti}$ alloys are mainly used for high-strength conductive springs, diaphragms, and corrosion- and wearresistant materials owing to their high tensile strength of over $700 \mathrm{MPa}$, good workability, and stress-relaxation properties. ${ }^{1-6)}$ However, the electrical conductivity of these alloys is less than $15 \%$ IACS, where \% IACS is the electrical conductivity relative to that of the International Annealed Copper Standard, which is inferior to that of commercial $\mathrm{Cu}-\mathrm{Be}$ alloys or $\mathrm{Cu}-\mathrm{Ni}-\mathrm{Si}$ alloys. $\left.{ }^{7-13}\right)$

The main reason for the relatively low electrical conductivity of $\mathrm{Cu}-\mathrm{Ti}$ alloys compared with $\mathrm{Cu}-\mathrm{Be}$ alloys and $\mathrm{Cu}-\mathrm{Ni}-\mathrm{Si}$ alloys is the presence of solute $\mathrm{Ti}$ in the $\mathrm{Cu}$ matrix. This means that the scattering of the conduction electrons by the impurity potential due to the solute Ti atoms is relatively high. According to Nordheim's rule combined with Matthiessen's rule, ${ }^{14)}$ the residual resistivity $\rho$ can be expressed as

$$
\rho=A x(1-x)+\rho_{0}
$$

where $x$ is the solute concentration, $A$ is the Nordheim coefficient, which is determined by the electronic interactions between the solute atoms and conduction electrons, and $\rho_{0}$ is the resistivity of the matrix due to scattering from lattice vibrations and other defects such as dislocations, stacking faults and point defects. For dilute solutions, because $x \ll 1$, $\rho$ can be approximated as follows:

$$
\rho \approx A x+\rho_{0}
$$

The value of $A$ for Ti ranges from $5 \mu \Omega \mathrm{cm} /$ at $\%$ to 12 $\mu \Omega \mathrm{cm} /$ at\% ${ }^{11,15-17)}$ and is very sensitive to the experimental conditions, whereas those for $\mathrm{Zn}, \mathrm{Ni}$, and $\mathrm{Sn}$ are $0.2,1.1$, and $2.7 \mu \Omega \mathrm{cm} /$ at $\%$, respectively; ${ }^{16)}$ thus, solute Ti atoms exert a very large influence on the conductivity compared with $\mathrm{Zn}, \mathrm{Ni}$, and $\mathrm{Sn}$. Consequently, it is crucial to determine the precise amount of solute $\mathrm{Ti}$ in the $\mathrm{Cu}$ matrix during the design of $\mathrm{Cu}-\mathrm{Ti}$ alloys.

*Corresponding author, E-mail: kondou@nagasaki-u.ac.jp
Furthermore, $\mathrm{Cu}-\mathrm{Ti}$ alloys exhibit spinodal decomposition during aging, 1,3,4,6,12,18-27) which is an interesting and attractive property from both academic and industrial perspectives. According to Cornie et al., ${ }^{1)}$ the spinodal decomposition process involves the development of $\langle 100\rangle$ compositional waves and formation of a periodic array of interpenetrating block-like rods along the $\langle 100\rangle$ directions of the matrix, which contributes to the strengthening of agehardened $\mathrm{Cu}-\mathrm{Ti}$ alloys; thus, spinodal decomposition is an industrially important phenomenon. Furthermore, measurements of the electrical resistivity of a $\mathrm{Cu}-4$ mass $\%$ Ti alloy at $77 \mathrm{~K}$ revealed that the electrical conductivity increased from $5.2 \%$ IACS to $14 \%$ IACS after annealing at $723 \mathrm{~K}$ for $1.08 \mathrm{ks},{ }^{18)}$ which indicates that the electrical conductivity increases with increasing spinodal decomposition. However, more dilute alloys such as $\mathrm{Cu}-1$ mass\% Ti have been shown to decompose predominantly by the mechanism of nucleation and growth. ${ }^{28)}$ Additionally, an investigation into the decomposition process of $\mathrm{Cu}-0.9$ at $\%$ Ti solid solutions after aging at $623 \mathrm{~K}$ by Borchers, ${ }^{29}$ ) which was based on the analysis of transmission electron microscopy (TEM) images and the energetics of nucleation aided by CALPHAD calculations, revealed the copious formation of nano-sized coherent ellipsoids or oblong particles from the onset of decomposition. However, Borchers suggested that the occurrence of classical nucleation as the initial step in the decomposition process is essentially precluded if the alloy is supersaturated. Concerning more concentrated $\mathrm{Cu}-\mathrm{Ti}$ alloys, $\mathrm{Cu}-5.17$ mass \% Ti alloy was indeed reported to be spinodal in nature by Laughlin and Cahn. ${ }^{3)}$ Therefore, the Ti content seems to exert a considerable influence on the decomposition process.

Supersaturated states of solute atoms can be achieved by various methods, such as rapid solidification processing (RSP) from the liquid state, mechanical alloying (MA) of solid elements, vapor deposition, laser processing, sputtering, and ion beam mixing. ${ }^{30)}$ In particular, RSP and MA are frequently used to form non-equilibrium phases such as amorphous alloys, ${ }^{31-34)}$ quasicrystals,${ }^{35-38)}$ and supersaturated solid solutions. 
Regarding the application of MA to the formation of supersaturated solid solutions, $\mathrm{Xi}$ et al. investigated the extension of the solid solubility of $\mathrm{Mo}$ in $\mathrm{Cu}^{39)}$ The solid solubility of $\mathrm{Mo}$ in the $\mathrm{Cu}$ matrix was found to be less than 4.3 at\% upon MA, whereas the equilibrium solid solubility of Mo is less than 0.06 at $\%$ even at the higher temperature of $1356 \mathrm{~K}$. Lei et al. investigated the solid solubility of $\mathrm{Nb}$ in $\mathrm{Cu}$ and found that it could be extended to more than $7 \mathrm{at} \%,{ }^{40)}$ whereas Mula et al. demonstrated that 7.5 at $\% \mathrm{Nb}$ could be dissolved in the $\mathrm{Cu}$ matrix on the basis of X-ray diffraction (XRD) analysis and the Gibbs free energy change. ${ }^{41)}$ These two reports indicate that the solid solubility extension of $\mathrm{Nb}$ is in the range of $7-7.5$ at $\%,{ }^{40,41)}$ which is considerably higher than the equilibrium solid solubility of $\mathrm{Nb}$ of approximately $0.1 \mathrm{at} \%{ }^{42}$ and indicates that MA greatly increases the solid solubility of $\mathrm{Nb}$ in the $\mathrm{Cu}$ matrix.

With respect to the use of RSP for the formation of supersaturated solid solutions, Bell and Davies reported the solid solubility extension in $\mathrm{Cu}-\mathrm{V}$ alloys. ${ }^{43)}$ The solid solubility of $\mathrm{V}$ in $\mathrm{Cu}$ was found to increase from the equilibrium value of 0.17 at $\%$ to 0.5 at $\%$, as determined by electrical resistivity measurements. Consequently, both the MA and RSP approaches seem to possess great potential for extending the solid solubility limit. Therefore, in this study, we investigated the solid solubility extension of $\mathrm{Cu}-\mathrm{Ti}$ alloys produced by the RSP technique of melt-spinning using XRD and TEM analysis, with a focus on solubility extension and spinodal decomposition.

In addition, as stated above, the $\mathrm{Ti}$ content exerts a considerable influence on the alloy decomposition process. However, the maximum dissolved Ti content appears to be limited to approximately 5 mass $\%$ for samples fabricated by conventional methods. Therefore, it remains unknown whether more concentrated $\mathrm{Cu}-\mathrm{Ti}$ alloys can also undergo spinodal decomposition; thus, it seems very intriguing and important to study the decomposition process for more concentrated and more supersaturated $\mathrm{Cu}-\mathrm{Ti}$ alloys fabricated by the RSP technique of melt-spinning.

\section{Experiments}

Small pieces of oxygen-free copper (99.99\%) and titanium $(99.99 \%)$ were combined in various weight ratios $(4,6,7$, or 8 mass $\%$ Ti) and melted in a high-frequency furnace under argon gas shielding. The alloy ingots were fabricated in an alumina crucible, however the reaction between the $\mathrm{Ti}$ and the crucible was not significant. Samples $(9 \times 9 \times 0.6 \mathrm{~mm}$, $0.4 \mathrm{~g}$ ) were cut from the alloy specimens and annealed at $1163 \mathrm{~K}$ for $10.8 \mathrm{ks}$ followed by quenching in iced water (a solution treatment with no further annealing processes).

Melt-spun specimens were fabricated under an argon gas atmosphere using a single-roller melt-spinning apparatus with a quartz nozzle. The melt-spun samples $(3 \mathrm{~g})$ were quenched from the liquid state at approximately $1523 \mathrm{~K}$ with a surface velocity of $42 \mathrm{~m} / \mathrm{s}$ and a blow-off pressure of $0.6 \mathrm{~atm}$ (As-Q samples). The melt-spun samples had a thickness of 50 $60 \mu \mathrm{m}$ and a width of $1-1.5 \mathrm{~mm}$ and were aged at $673 \mathrm{~K}$ for 0 (As-Q), 1.8, 3.6, or $7.2 \mathrm{ks}$. After liquid quenching, small amounts of residue were observed in the quartz nozzle, which may indicate reaction between the nozzle and Ti.
Additionally, the melt-spun samples with 7 and 8 mass $\%$ Ti were aged at $773 \mathrm{~K}$ for $1.8,3.6$, or $7.2 \mathrm{ks}$ to examine the precipitation at a higher aging temperature.

XRD analysis was performed using a $\mathrm{Cu}-\mathrm{K} \alpha$ radiation source to assess whether sidebands and new ordered phases had formed during aging. In particular, to detect the presence of sidebands corresponding to the 200 planes, step scanning was performed from $47^{\circ}$ to $53^{\circ}$ at a scanning speed of $0.3^{\circ} / \mathrm{min}$, based on the scanning speed of $0.25^{\circ} / \mathrm{min}$ reported by Findik. ${ }^{44)}$

TEM analysis was performed for the melt-spun samples of the $\mathrm{Cu}-6$ mass\% Ti alloy aged at $673 \mathrm{~K}$ for $3.6 \mathrm{ks}$ and the $\mathrm{Cu}-7$ mass\% Ti alloy aged at $673 \mathrm{~K}$ for $3.6 \mathrm{ks}$ and $7.2 \mathrm{ks}$ to examine the spinodal decomposition process. Discs with a diameter of approximately $3 \mathrm{~mm}$ were punched from the samples and polished by ion milling. High-resolution TEM (JEM-2010, JEOL) operating at $200 \mathrm{kV}$ was then used to observe the microstructures and conduct selected-area diffraction pattern (SADP) analysis. In the SADP measurements using a CCD camera, two exposure times were used: one for the satellite structures $(0.1 \mathrm{~s})$ and another for the superlattice reflections ( $1.0 \mathrm{~s})$. As noted by Zhao and Notis, ${ }^{45)}$ SADP results are dependent on the exposure time. A short exposure time is preferred for measuring spinodal satellites because the bright fundamental reflections obtained after long exposure times tend to wash out the satellites. In contrast, a long exposure time is required to observe superlattice reflections.

\section{Results and Discussion}

Figure 1 shows a partial phase diagram for the $\mathrm{Cu}-\mathrm{Ti}$ binary system, ${ }^{46)}$ which implies the possibility of $\mathrm{Cu}_{4} \mathrm{Ti}$ precipitations with increasing $\mathrm{Ti}$ content. Concerning the $\mathrm{Cu}_{4} \mathrm{Ti}$ precipitations, two ordered phases have been reported. One is a metastable coherent precipitate known as the

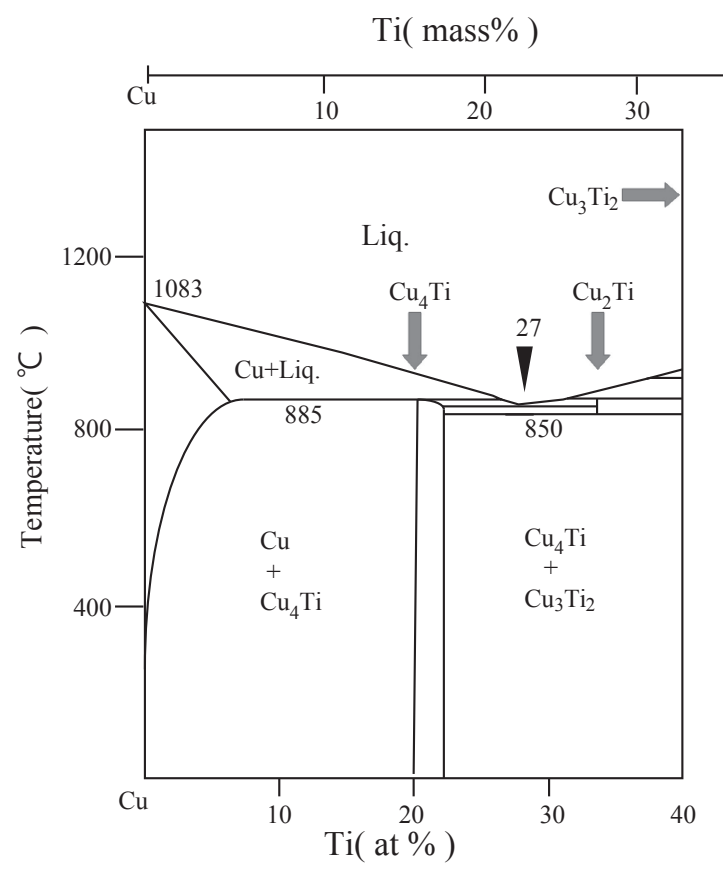

Fig. 1 Partial phase diagram for the $\mathrm{Cu}-\mathrm{Ti}$ binary system. 


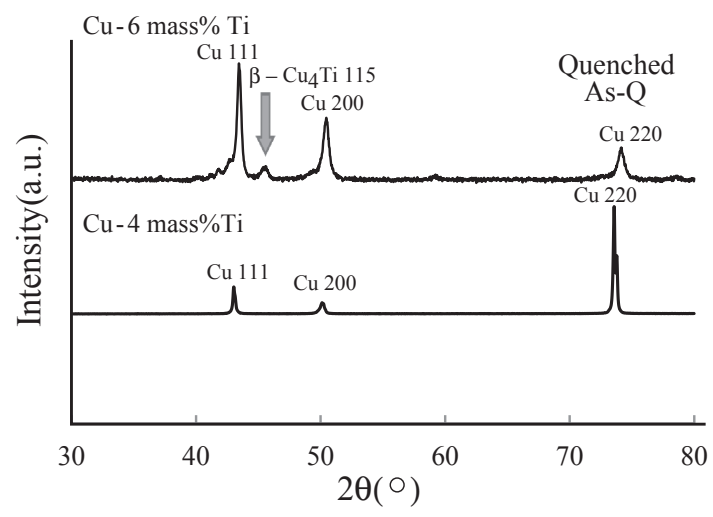

Fig. 2 XRD spectra of the quenched samples of the $\mathrm{Cu}-4$ mass\% Ti and $\mathrm{Cu}-6$ mass $\%$ Ti alloys.

metastable $\alpha-\mathrm{Cu}_{4} \mathrm{Ti}$ phase with a tetragonal $\mathrm{D} 1_{\mathrm{a}}$ structure $\left(a=0.587 \mathrm{~nm}\right.$ and $c=0.365 \mathrm{~nm}$, prototype, $\mathrm{Ni}_{4} \mathrm{Mo}$; space group, $I 4 / \mathrm{m}),{ }^{3,4)}$ and the other is a stable $\beta-\mathrm{Cu}_{4} \mathrm{Ti}$ phase with an ordered orthorhombic structure $(a=0.4528 \mathrm{~nm}, b=$ $0.4345 \mathrm{~nm}$ and $c=1.2932 \mathrm{~nm}$, prototype, $\mathrm{Au}_{4} \mathrm{Zr}$; space group, $\mathrm{P}$ nma), which is formed in the grain boundaries during prolonged aging. ${ }^{3,4)}$

Figure 2 shows the XRD spectra of the quenched samples of As-Q states from $30^{\circ}$ to $80^{\circ}$. For the quenched $\mathrm{Cu}-$ 6 mass $\%$ Ti sample, a peak corresponding to the 115 reflection of the stable $\beta$ - $\mathrm{Cu}_{4}$ Ti phase was observed at a $2 \theta$ value of approximately $45^{\circ}$, whereas no peaks except $\mathrm{Cu}$ phases were observed in the $\mathrm{Cu}-4$ mass\% $\mathrm{Ti}$ sample. As predicted from Fig. 1, a $\mathrm{Cu}_{4} \mathrm{Ti}$ phase-specifically, the stable $\beta-\mathrm{Cu}_{4} \mathrm{Ti}$ phase-appeared at a Ti content of $6 \operatorname{mass} \%$.

In the early stage of the spinodal decomposition of a $\mathrm{Cu}-\mathrm{Ti}$ alloy, the supersaturated solid solution of $\mathrm{Cu}$ decomposes into two phases, namely, Ti-rich and Ti-lean regions. Subsequently, clusters form in the Ti-rich region and become ordered to generate a metastable coherent $\alpha-\mathrm{Cu}_{4} \mathrm{Ti}$ precipitate. Upon quenching the $\mathrm{Cu}-4$ mass $\% \mathrm{Ti}$ alloy, there seemed to be insufficient time to precipitate the stable $\beta$ $\mathrm{Cu}_{4} \mathrm{Ti}$ phase from the Ti-rich region owing to the high cooling rate of about $10^{3} \mathrm{~K} / \mathrm{s}$. However, for the $\mathrm{Cu}-6$ mass $\%$ Ti alloy, the high cooling rate was not sufficient to prevent the formation of the stable $\beta-\mathrm{Cu}_{4} \mathrm{Ti}$ phase in the Ti-rich region. Furthermore, as illustrated in Fig. 1, two phases $(\mathrm{Cu}$ and $\beta$ $\mathrm{Cu}_{4} \mathrm{Ti}$ ) appear to coexist even up to $1158 \mathrm{~K}$ for a Ti content of 6 mass $\%$. Therefore, in the homogenization treatment applied here (annealing at $1163 \mathrm{~K}$ for $10.8 \mathrm{ks}$ prior to quenching in iced water), two phases presumably coexist; consequently, we speculate that the precipitation of the stable $\beta-\mathrm{Cu}_{4}$ Ti phase is due to the equilibrium phase diagram and/or insufficient cooling rate. We conclude that the solid solubility extension of $\mathrm{Ti}$ is less than 6 mass $\%$ for the quenching process.

According to the XRD data, the stable $\beta-\mathrm{Cu}_{4} \mathrm{Ti}$ phase was formed rather than the metastable $\alpha-\mathrm{Cu}_{4} \mathrm{Ti}$ phase, which was ascribed to the rapid cooling rate. As the metastable $\alpha$ phase is formed at a lower temperature than the $\beta$ phase, the cooling rate of $10^{3} \mathrm{~K} / \mathrm{s}$ appears to be too high to allow formation of the $\alpha$ phase.

Figure 3 shows the XRD spectra of the melt-spun As-Q alloys with Ti contents of $4,6,7$, and 8 mass $\%$. No peaks except those corresponding to the $\mathrm{Cu}$ phase were observed

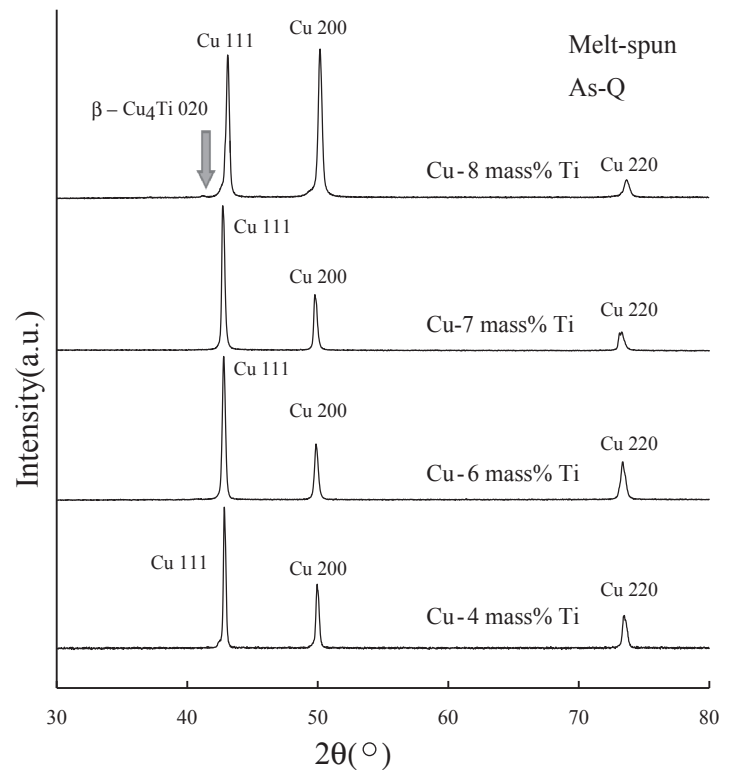

Fig. 3 XRD spectra of the melt-spun As-Q samples of the $\mathrm{Cu}-4$ mass\% $\mathrm{Ti}$, $\mathrm{Cu}-6 \mathrm{mass} \% \mathrm{Ti}, \mathrm{Cu}-7$ mass\% $\mathrm{Ti}$, and $\mathrm{Cu}-8$ mass\% $\mathrm{Ti}$ alloys.

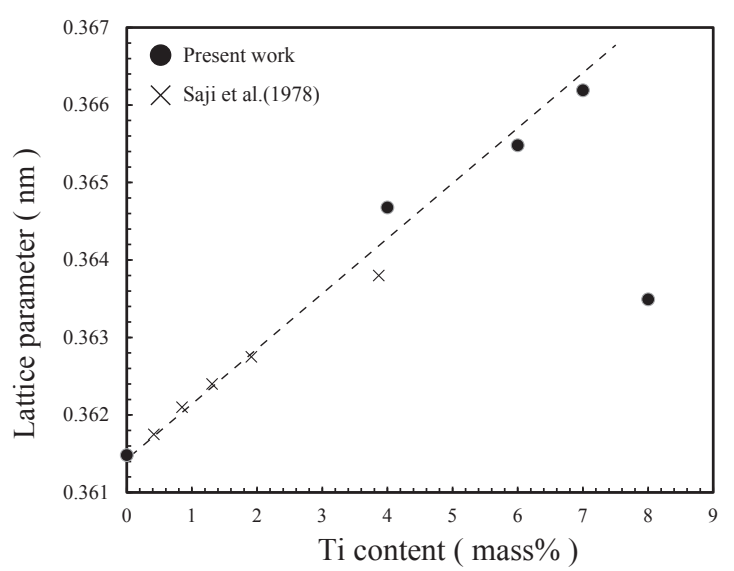

Fig. 4 Lattice parameters of the melt-spun As-Q samples of the $\mathrm{Cu}-$ 4 mass $\%$ Ti, $\mathrm{Cu}-6$ mass $\%$ Ti, Cu-7 mass\% Ti, and $\mathrm{Cu}-8$ mass\% Ti alloys together with those obtained in the work by Saji et al. ${ }^{48)}$

when the Ti content was less than 7 mass \%; however, a very minor $\beta$ - $\mathrm{Cu}_{4}$ Ti 020 peak was detected in the vicinity of the $\mathrm{Cu} 111$ peak in the spectrum of the $\mathrm{Cu}-8$ mass\% $\mathrm{Ti}$ alloy. Therefore, we conclude that the solid solubility extension of Ti is less than 8 mass\% for samples fabricated using RSP (melt-spinning).

In contrast to conventional quenching, the melt-spinning procedure leads to very rapid quenching of the molten metal at a cooling rate of approximately $8 \times 10^{5} \mathrm{~K} / \mathrm{s}$, ${ }^{47)}$ which does not permit sufficient time for the single liquid phase to decompose into two phases (Ti-rich and Ti-lean regions). The experimental observation of a slight peak corresponding to the stable $\beta-\mathrm{Cu}_{4} \mathrm{Ti}$ phase in the $\mathrm{Cu}-8$ mass $\%$ Ti alloy, however, suggests that the rapid cooling rate of about $8 \times 10^{5} \mathrm{~K} / \mathrm{s}$ does not prevent nucleation during the solidification process.

The lattice parameters of the melt-spun As-Q alloys with Ti contents of 4, 6, 7, and 8 mass $\%$ are illustrated in Fig. 4 together with those obtained in the work by Saji et al. ${ }^{48)}$ To 


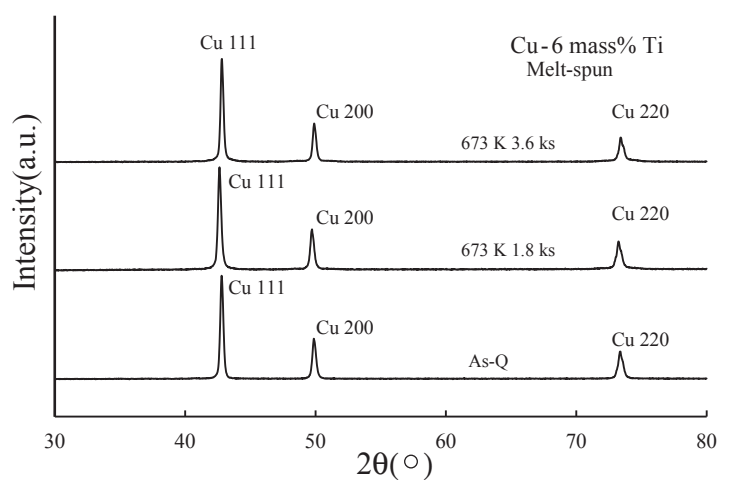

Fig. 5 XRD spectra of the melt-spun $\mathrm{Cu}-6$ mass\% Ti alloy samples aged at $673 \mathrm{~K}$ for 0 (As-Q), 1.8, and $3.6 \mathrm{ks}$.

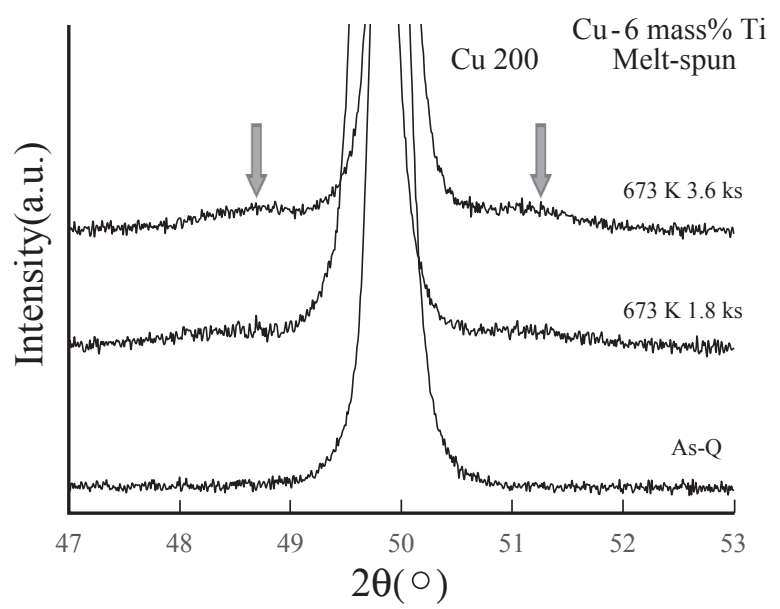

Fig. 6 Step scanning results around the $\mathrm{Cu}(200)$ diffraction peak for the melt-spun $\mathrm{Cu}-6$ mass $\%$ Ti alloy samples aged at $673 \mathrm{~K}$ for 0 (As-Q), 1.8 , and $3.6 \mathrm{ks}$.

determine the lattice parameters, we used the program RIETAN-FP. ${ }^{49)}$ From this figure, the lattice parameter was found to be proportional to the $\mathrm{Ti}$ content except for the $\mathrm{Cu}-8$ mass\% Ti alloy, which means that Vegard's law holds. By combining Vegard's law with the XRD results shown in Fig. 3, we can conclude that 7 mass $\%$ Ti dissolves in the $\mathrm{Cu}$ matrix. In contrast, the lattice parameter of the melt-spun $\mathrm{Cu}-8$ mass\% Ti alloy deviates from Vegard's law. This deviation is presumably attributable to the precipitation of the stable $\beta-\mathrm{Cu}_{4} \mathrm{Ti}$ phase as shown in Fig. 3.

Figure 5 shows the XRD spectra of the melt-spun $\mathrm{Cu}-$ 6 mass $\%$ Ti alloys aged at $673 \mathrm{~K}$ for 0 (As-Q), 1.8, and $3.6 \mathrm{ks}$. Only the $\mathrm{Cu}$ phase was observed in all cases, and no peaks corresponding to the metastable or stable $\mathrm{Cu}_{4} \mathrm{Ti}$ phases $(\alpha$ $\mathrm{Cu}_{4} \mathrm{Ti}$ or $\beta-\mathrm{Cu}_{4} \mathrm{Ti}$, respectively) were detected. Therefore, it appears that the annealing temperature of $673 \mathrm{~K}$ and annealing time of $3.6 \mathrm{ks}$ are not sufficient for forming these $\mathrm{Cu}_{4} \mathrm{Ti}$ phases and/or other intermetallic compounds.

Figure 6 shows the step scanning results from $47^{\circ}$ to $53^{\circ}$ for the melt-spun $\mathrm{Cu}-6$ mass\% Ti samples. As indicated by the arrows, sidebands were clearly visible for the sample annealed for $3.6 \mathrm{ks}$, and slight sidebands were also detected for the sample annealed for $1.8 \mathrm{ks}$. Therefore, the spinodal decomposition process appears to be favored by longer annealing times. (a)

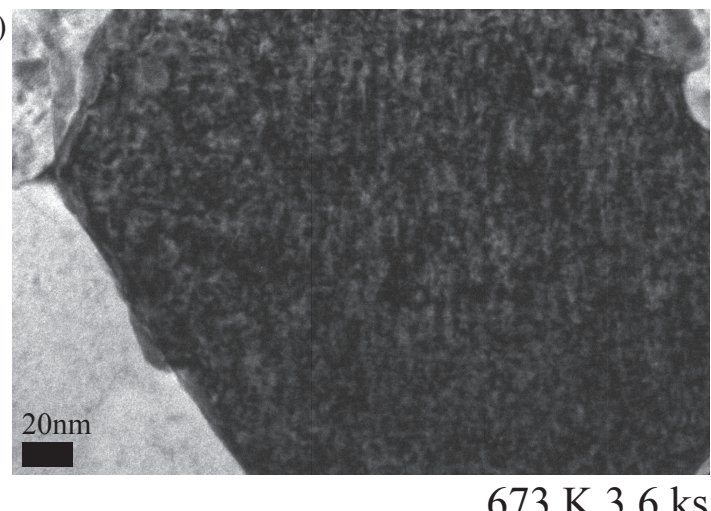

(b)

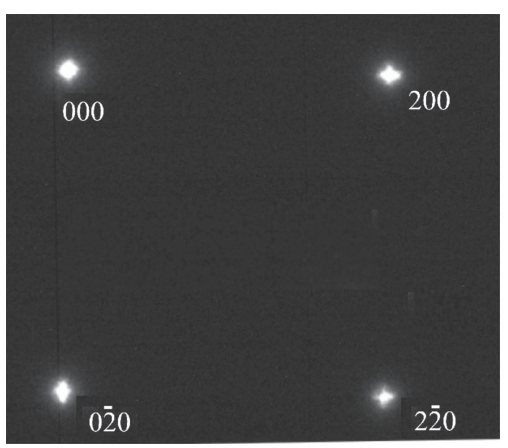

(c)

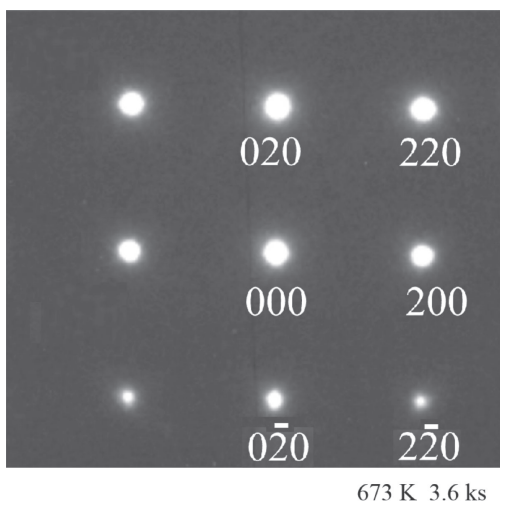

Fig. 7 TEM results for the melt-spun $\mathrm{Cu}-6$ mass $\%$ Ti alloy sample aged at $673 \mathrm{~K}$ for $3.6 \mathrm{ks}$ : (a) BF TEM image, (b) SADP (exposure time $0.1 \mathrm{~s}$ ), (c) SADP (exposure time $1.0 \mathrm{~s}$ ).

The wavelength, $\lambda$, of the spinodal decomposition was evaluated using the Daniel-Lipson formula: ${ }^{50-52)}$

$$
\lambda=a_{0} \frac{h \tan \theta}{\left(h^{2}+k^{2}+l^{2}\right) \delta \theta}
$$

where $\theta$ is the Bragg angle of the fundamental cubic peak, $\delta \theta$ is the difference in angle between the sideband and the Bragg peak, $a_{0}$ is the lattice parameter of the matrix alloy in its initial state prior to spinodal decomposition, and $h, k$, and $l$ are the Miller indices of the Bragg peak $(h=2$ and $k=$ $l=0$ ). From eq. (2), we obtain $\lambda \approx 7.8 \mathrm{~nm}$ for the sample annealed for $3.6 \mathrm{ks}$.

In an effort to confirm the occurrence of spinodal decomposition, we examined the alloy microstructure by TEM and electron diffraction. Figure 7(a) shows bright-field (BF) TEM images of the melt-spun $\mathrm{Cu}-6$ mass $\%$ Ti alloy sample after annealing for $3.6 \mathrm{ks}$, revealing modulated structures characteristic of spinodal decomposition. Although it is difficult to precisely determine the value of $\lambda$, it was 


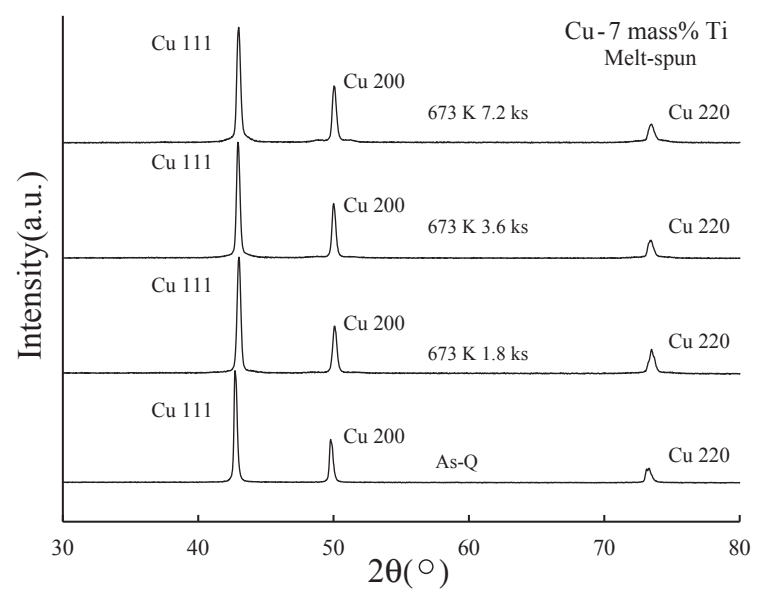

Fig. 8 XRD spectra of the melt-spun $\mathrm{Cu}-7$ mass $\%$ Ti alloy samples aged at $673 \mathrm{~K}$ for 0 (As-Q), 1.8, 3.6, and $7.2 \mathrm{ks}$.

roughly estimated to be approximately $5-10 \mathrm{~nm}$, which is in good agreement with the calculated value of $7.8 \mathrm{~nm}$ obtained using eq. (2).

Figure 7(b) shows an SADP of the same sample with an exposure time of $0.1 \mathrm{~s}$. As expected from Fig. 7(a), distinct satellites caused by structural modulation were observed. Furthermore, it should be noted that the 000 reflection also showed satellites, which is presumably attributable to the short exposure time of $0.1 \mathrm{~s}$ and the enhancement of concentration fluctuations. Figure 7(c) shows an SADP of the same sample with an exposure time of $1.0 \mathrm{~s}$, where no long-range ordering (LRO) was observed.

Figure 8 shows the XRD spectra of the melt-spun $\mathrm{Cu}-$ 7 mass $\%$ Ti alloys aged at $673 \mathrm{~K}$ for 0 (As-Q), 1.8, 3.6, and $7.2 \mathrm{ks}$. Similar to the results for the melt-spun $\mathrm{Cu}-6$ mass\% $\mathrm{Ti}$ alloys, the XRD results for the $\mathrm{Cu}-7$ mass\% $\mathrm{Ti}$ alloys contained no peaks corresponding to metastable or stable $\mathrm{Cu}_{4} \mathrm{Ti}$ phases $\left(\alpha-\mathrm{Cu}_{4} \mathrm{Ti}\right.$ or $\beta-\mathrm{Cu}_{4} \mathrm{Ti}$, respectively) and only revealed reflections from a single $\mathrm{Cu}$ phase, which implies that no precipitates and/or metastable intermetallic compounds were formed even after annealing for $7.2 \mathrm{ks}$. However, the XRD intensity around the $\mathrm{Cu} 200$ peak appeared to increase slightly for the sample annealed for $7.2 \mathrm{ks}$, indicating the presence of sidebands.

Figure 9 shows the step scanning results for the melt-spun 7 mass $\%$ Ti samples. As indicated by the arrows, sidebands were clearly visible for the samples annealed for 3.6 and $7.2 \mathrm{ks}$, which suggests the occurrence of spinodal decomposition. Using eq. (2), we obtained $\lambda$ values of approximately 6.8 and $8.2 \mathrm{~nm}$ for the samples annealed for 3.6 and $7.2 \mathrm{ks}$, respectively; thus, we conclude that spinodal decomposition increased with increasing annealing time.

Figure 10(a) shows a BF TEM image of the melt-spun sample of $\mathrm{Cu}-7$ mass $\%$ Ti after annealing for $3.6 \mathrm{ks}$, revealing a modulated structure. Although it is difficult to precisely evaluate the value of $\lambda$ from this image, we estimate that it is less than $10 \mathrm{~nm}$.

Figure 10(b) shows an SADP of the same sample with an exposure time of $0.1 \mathrm{~s}$. As in the case of Fig. 7(c), distinct satellites due to structural modulation were observed. Figure 10(c) shows an SADP of the same sample with an exposure time of $1.0 \mathrm{~s}$. Weak spots were detected around the

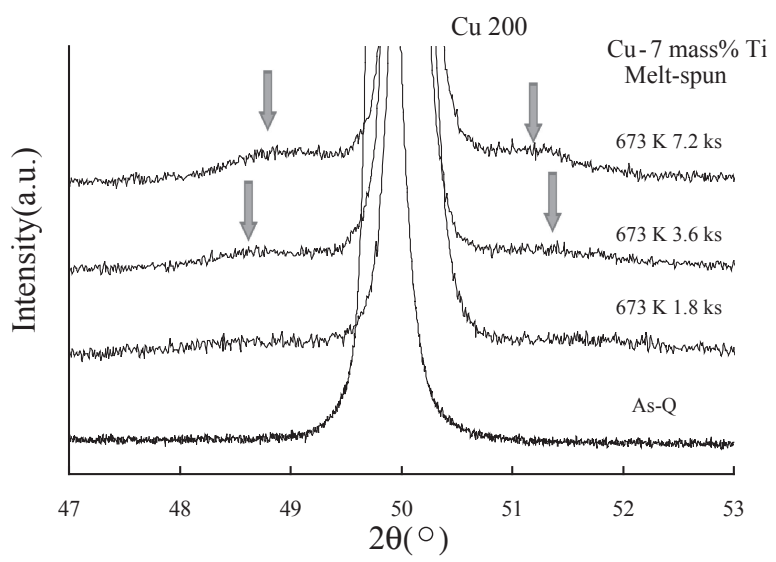

Fig. 9 Step scanning results around the $\mathrm{Cu}(200)$ diffraction peak for the melt-spun $\mathrm{Cu}-7$ mass \% Ti alloy samples aged at $673 \mathrm{~K}$ for 0 (As-Q), 1.8, 3.6 , and $7.2 \mathrm{ks}$.

(200), (020), and (220) reflections. Concerning the SADPs of melt-spun $\mathrm{Cu}-\mathrm{Ti}$ alloys, Batra et al. reported the initial appearance of spots corresponding to the $\mathrm{N}_{3} \mathrm{M}$ phase, the structure of which can be visualized as a space-filling arrangement of unimolecular clusters of $\mathrm{Ni}_{4} \mathrm{Mo}\left(D 1_{\mathrm{a}}\right)$ and $\mathrm{Ni}_{2} \mathrm{Mo}\left(\mathrm{Pt}_{2} \mathrm{Mo}\right.$-type $){ }^{28)}$ According to this report, ${ }^{28)}$ these spots disappeared upon further aging at $673 \mathrm{~K}$, whereupon $D 1_{\text {a }}$ superlattice reflections started to increase in intensity; thus, the $\mathrm{N}_{3} \mathrm{M}$ phase is considered a precursor to the formation of the metastable $D 1_{\text {a }}$ phase. Our experimental result shown in Fig. 10 (c) is entirely different, with no $\mathrm{N}_{3} \mathrm{M}$ or $D 1_{\mathrm{a}}$ reflections observed: $1 / 5\{420\}$ and equivalent spots belonging to the two variants of the $\mathrm{D} 1_{\mathrm{a}}$ phase (metastable $\alpha-\mathrm{Cu}_{4} \mathrm{Ti}$ phase), $\left\{\begin{array}{lll}1 & \frac{1}{2} & 0\end{array}\right\}$ and equivalent spots, and $\left\{\begin{array}{lll}\frac{1}{2} & \frac{1}{2} & 0\end{array}\right\}$ and equivalent spots of the $\mathrm{N}_{3} \mathrm{M}$ phase were not present. Instead, 110 spots as indicated by arrow, which do not belong to either the $\mathrm{D} 1_{\mathrm{a}}$ phase or the $\mathrm{N}_{3} \mathrm{M}$ phase, were clearly visible around the 200, 020, and 220 fundamental reflections. These differences are considered to originate from the differences in Ti concentration or observed area. Consequently, the spots observed in the vicinity of the 200, 020, and 220 reflections are considered to correspond to short-range ordering (SRO) and/or certain oxide reflections, although further analysis and experiments are necessary for definitive identification.

Figure 11(a) shows a BF TEM image of the melt-spun sample of $\mathrm{Cu}-7$ mass\% $\mathrm{Ti}$ after annealing for $7.2 \mathrm{ks}$, revealing a modulated structure. From this image, we estimate that the value of $\lambda$ is approximately $10 \mathrm{~nm}$.

Figure 11(b) shows an SADP of the same sample with an exposure time of $0.1 \mathrm{~s}$. As in the cases of Figs. 7(b) and 10(b), distinct satellites due to structural modulation were observed. Figure 11(c) shows an SADP of the same sample with an exposure time of $1.0 \mathrm{~s}$, revealing no LRO reflections. Although we were unable to identify the small mist-like spots around 000 , these may be due to SRO and/or oxide reflections.

Figure 12 shows the XRD spectra of the melt-spun $\mathrm{Cu}-$ 8 mass $\%$ Ti alloys aged at $673 \mathrm{~K}$ for 0 (As-Q), 1.8, 3.6, and $7.2 \mathrm{ks}$. As discussed previously for Fig. 3, a weak peak corresponding to the stable $\beta-\mathrm{Cu}_{4} \mathrm{Ti} 020$ phase was observed in the vicinity of the $\mathrm{Cu} 111$ peak. Despite the detection of the stable intermetallic $\beta$ - $\mathrm{Cu}_{4} \mathrm{Ti}$ phase, the intensity of this peak 
(a)

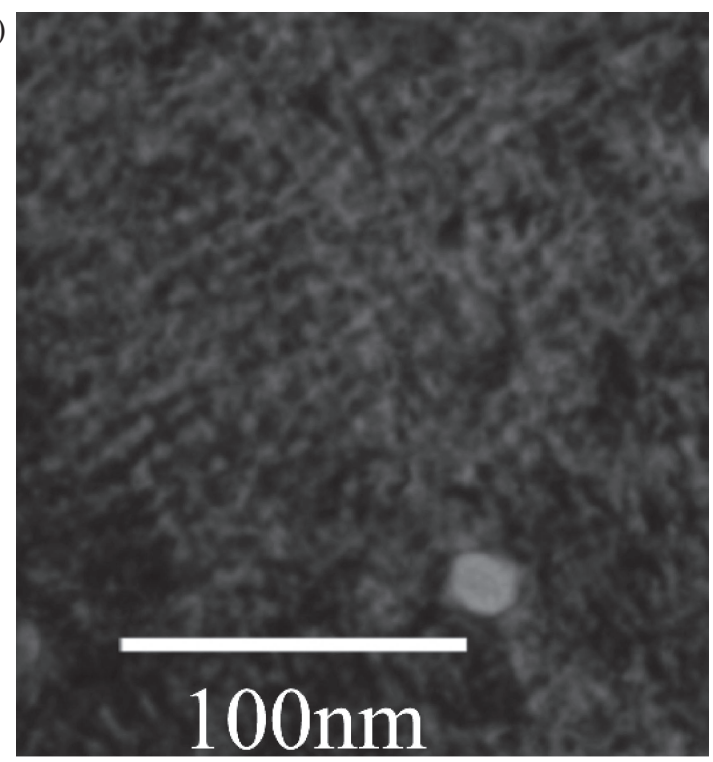

$673 \mathrm{~K} 3.6 \mathrm{ks}$

(b)

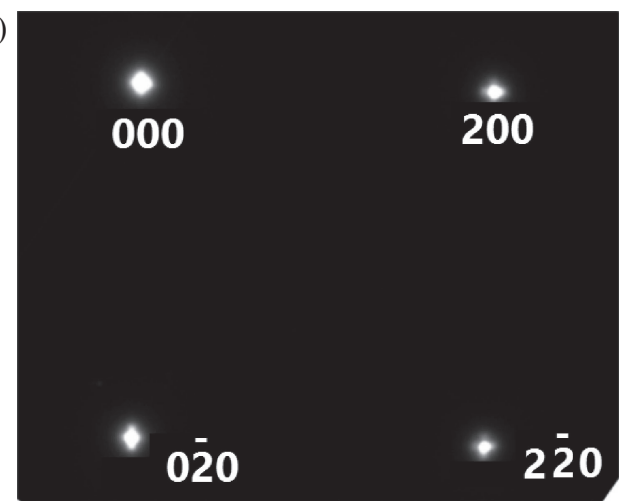

(c)

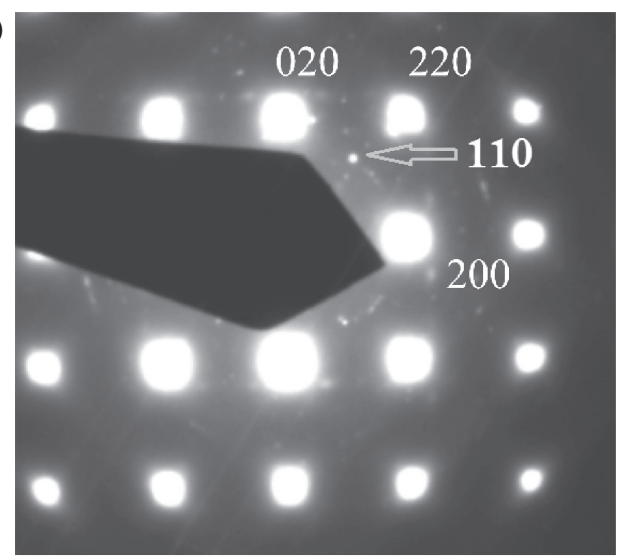

$673 \mathrm{~K} 3.6 \mathrm{ks}$

Fig. 10 TEM results for the melt-spun $\mathrm{Cu}-7$ mass $\%$ Ti alloy sample aged at $673 \mathrm{~K}$ for $3.6 \mathrm{ks}$ : (a) BF TEM image, (b) SADP (exposure time $0.1 \mathrm{~s}$ ), (c) SADP (exposure time $1.0 \mathrm{~s}$ ).

did not appear to increase upon prolonged aging. In contrast, a reflection ascribed to metastable $\alpha-\mathrm{Cu}_{4}$ Ti 310 was observed in the vicinity of the $\mathrm{Cu} 200$ peak after annealing for $7.2 \mathrm{ks}$. Since this phase was observed after an annealing time of $7.2 \mathrm{ks}$, the metastable $\alpha-\mathrm{Cu}_{4} \mathrm{Ti}$ phase is considered to grow during the annealing process.

Figure 13 shows the relative intensities $I / I(200)$, where $I(200)$ denotes the intensity of the $\mathrm{Cu} 200$ reflection, to (a)

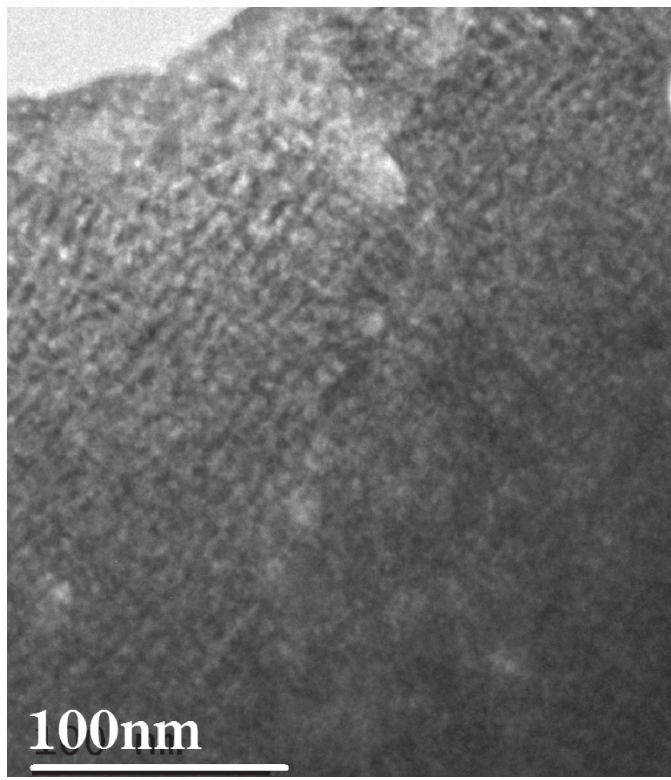

$673 \mathrm{~K} 7.2 \mathrm{ks}$

(b)

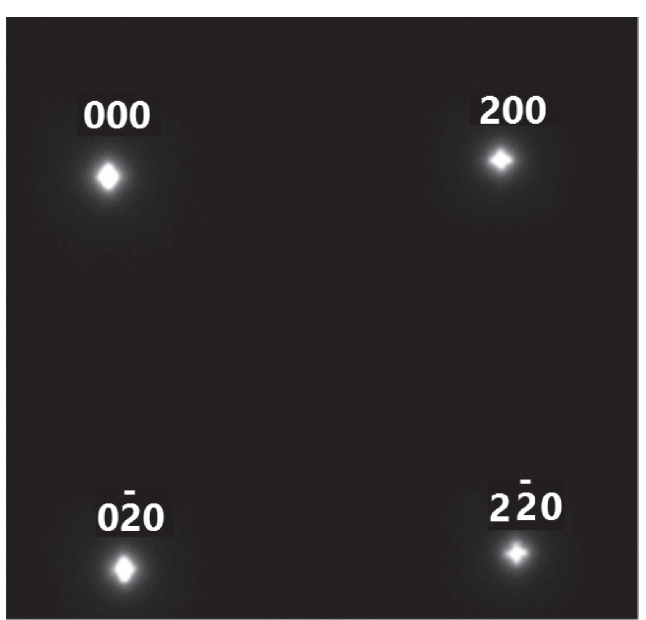

(c)

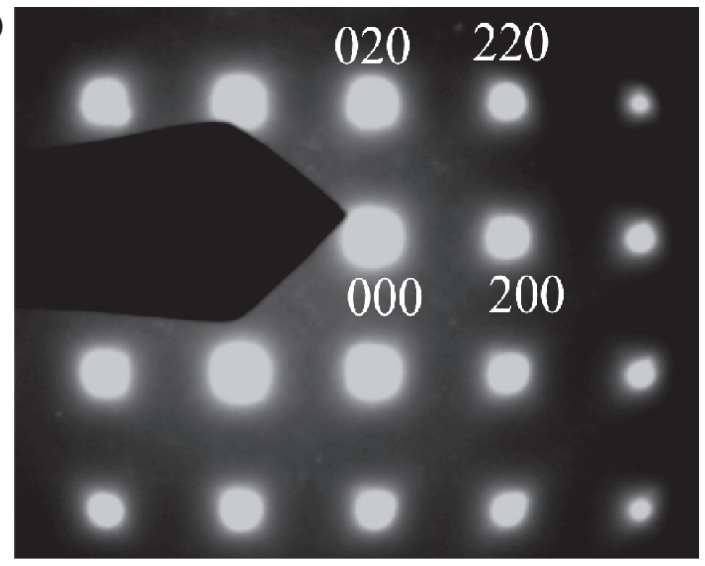

$673 \mathrm{~K} 7.2 \mathrm{ks}$

Fig. 11 TEM results for the melt-spun $\mathrm{Cu}-7$ mass\% Ti alloy sample aged at $673 \mathrm{~K}$ for $7.2 \mathrm{ks}$ : (a) BF TEM image, (b) SADP (exposure time $0.1 \mathrm{~s}$ ), (c) SADP (exposure time $1.0 \mathrm{~s}$ ).

investigate the growth of the stable $\beta$ - $\mathrm{Cu}_{4} \mathrm{Ti}$ phase. Although this comparison is not sufficiently precise to definitively measure the growth of the stable $\beta-\mathrm{Cu}_{4} \mathrm{Ti}$ phase with annealing time, the relative intensity of the stable $\beta-\mathrm{Cu}_{4} \mathrm{Ti}$ 


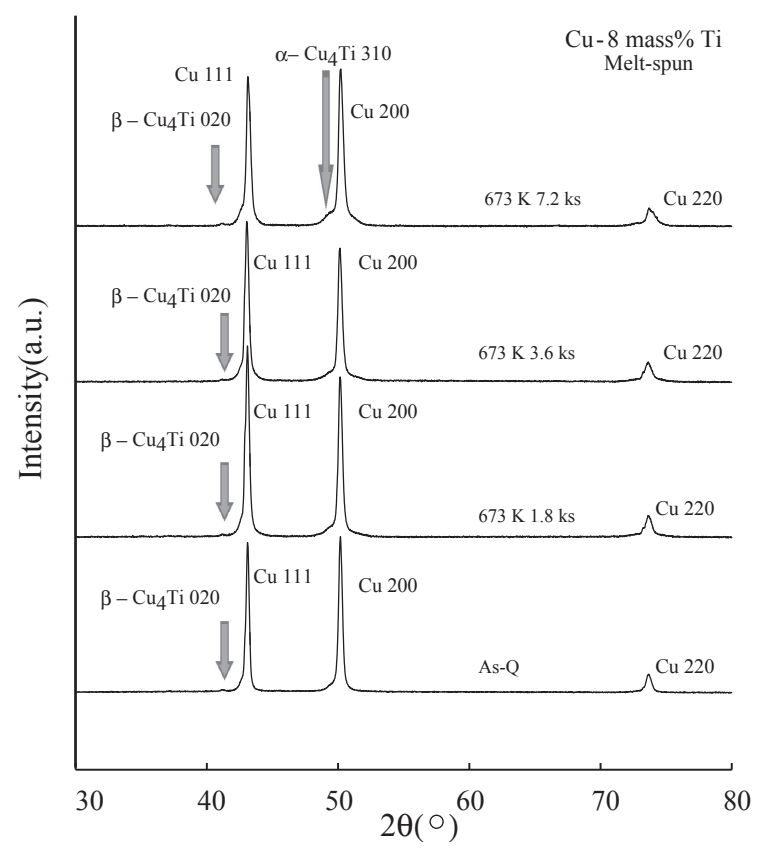

Fig. 12 XRD spectra of the melt-spun $\mathrm{Cu}-8$ mass $\%$ Ti alloy samples aged at $673 \mathrm{~K}$ for 0 (As-Q), 1.8, 3.6, and $7.2 \mathrm{ks}$.

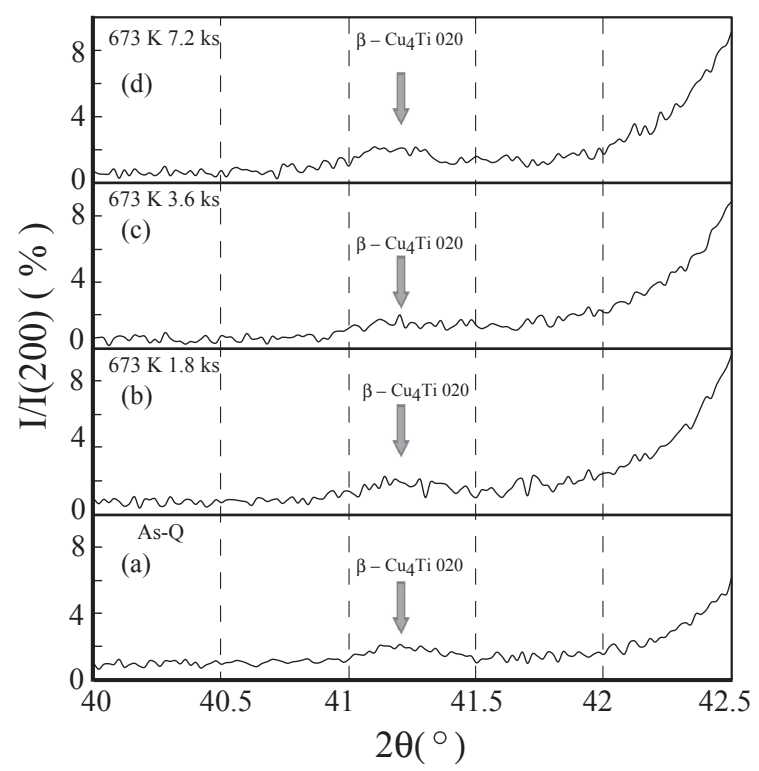

Fig. 13 Relative intensities $I / I(200)$ for the melt-spun $\mathrm{Cu}-8$ mass\% $\mathrm{Ti}$ alloy samples annealed at $673 \mathrm{~K}$ for (a) 0 (As-Q), (b) 1.8 , (c) 3.6, and (d) $7.2 \mathrm{ks}$, where $I(200)$ denotes the intensity of the $\mathrm{Cu}(200)$ reflection.

phase appears to remain constant regardless of aging time (the maximum value of $I / I(200)$ is approximately $2 \%$ throughout Figs. 13(a)-(d)). Therefore, it appears that the $\beta$ - $\mathrm{Cu}_{4} \mathrm{Ti}$ phase does not grow at this annealing time and annealing temperature. One reason for this could be that the stable $\beta$ - $\mathrm{Cu}_{4} \mathrm{Ti}$ phase introduced during the cooling process is a high-temperature phase stable above approximately $773 \mathrm{~K}^{.53)}$ consequently, the annealing temperature of $673 \mathrm{~K}$ is not sufficiently high for the growth of this phase.

Figure 14 shows the XRD spectra of the melt-spun $\mathrm{Cu}-$ 7 mass $\%$ Ti alloys aged at $773 \mathrm{~K}$ for 0 (As-Q), 1.8, 3.6, and $7.2 \mathrm{ks}$. As illustrated in this figure, the metastable $\alpha-\mathrm{Cu}_{4} \mathrm{Ti}$ phase first appears in the vicinity of the $\mathrm{Cu} 111$ and 200

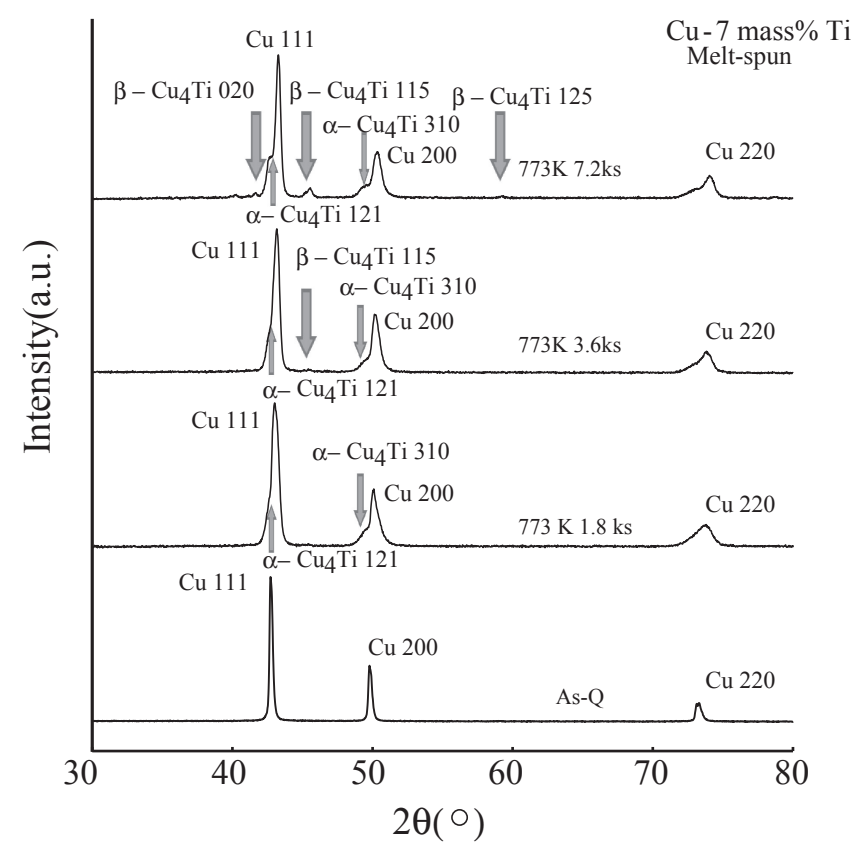

Fig. 14 XRD spectra of the melt-spun $\mathrm{Cu}-7$ mass\% Ti alloy samples aged at $773 \mathrm{~K}$ for 0 (As-Q), 1.8, 3.6, and $7.2 \mathrm{ks}$.

fundamental peaks after annealing for $1.8 \mathrm{ks}$. However, the stable $\beta$ - $\mathrm{Cu}_{4} \mathrm{Ti}$ phase does not appear before an annealing time of $3.6 \mathrm{ks}$; thus, the metastable $\alpha-\mathrm{Cu}_{4} \mathrm{Ti}$ phase would be expected to appear prior to the precipitation of the stable $\beta-\mathrm{Cu}_{4} \mathrm{Ti}$ phase. The appearance of such a new phase was never observed, even for the sample aged at $673 \mathrm{~K}$ for $7.2 \mathrm{ks}$ (see Fig. 8). Consequently, a higher aging temperature easily promotes the precipitation of the metastable $\alpha-\mathrm{Cu}_{4} \mathrm{Ti}$ phase and the stable $\beta$ - $\mathrm{Cu}_{4} \mathrm{Ti}$ phase.

Figure 15 shows the XRD spectra of the melt-spun $\mathrm{Cu}-$ 8 mass $\%$ Ti alloys aged at $773 \mathrm{~K}$ for 0 (As-Q), 1.8, 3.6, and $7.2 \mathrm{ks}$. In contrast to Fig. 14 , both the metastable $\alpha-\mathrm{Cu}_{4} \mathrm{Ti}$ phase and the stable $\beta-\mathrm{Cu}_{4} \mathrm{Ti}$ phase were clearly and simultaneously observed. This difference is presumably attributable to the higher concentration of $\mathrm{Ti}$ in $\mathrm{Cu}-8$ mass\% Ti. Therefore, from the results shown in Figs. 14 and 15, it appears that a higher annealing temperature and an increased $\mathrm{Ti}$ concentration are the driving forces for forming both the metastable $\alpha-\mathrm{Cu}_{4}$ Ti phase and the stable $\beta-\mathrm{Cu}_{4} \mathrm{Ti}$ phase.

\section{Conclusion}

We investigated the solid solubility extension in melt-spun $\mathrm{Cu}-\mathrm{Ti}$ alloys using a combination of XRD and TEM. The results revealed that the solid solubility extension of $\mathrm{Ti}$ in the $\mathrm{Cu}$ matrix is in the range of 7-8 mass \% $\mathrm{Ti}$, whereas the solid solubility was less than 6 mass $\% \mathrm{Ti}$ for samples fabricated using the conventional method (quenched samples). The difference in solid solubility between the melt-spun and quenched samples is due to the different cooling rates. The extremely high cooling rate of approximately $8 \times 10^{5} \mathrm{~K} / \mathrm{s}$ used for the melt-spun samples easily leads to more Ti being dissolved in the $\mathrm{Cu}$ matrix. However, as pointed out by $\mathrm{Xi}$ et al. ${ }^{38)}$ and Mula et al., ${ }^{40)}$ a greater amount of $\mathrm{Ti}$ can be expected to dissolve in the $\mathrm{Cu}$ matrix with the use of MA. 


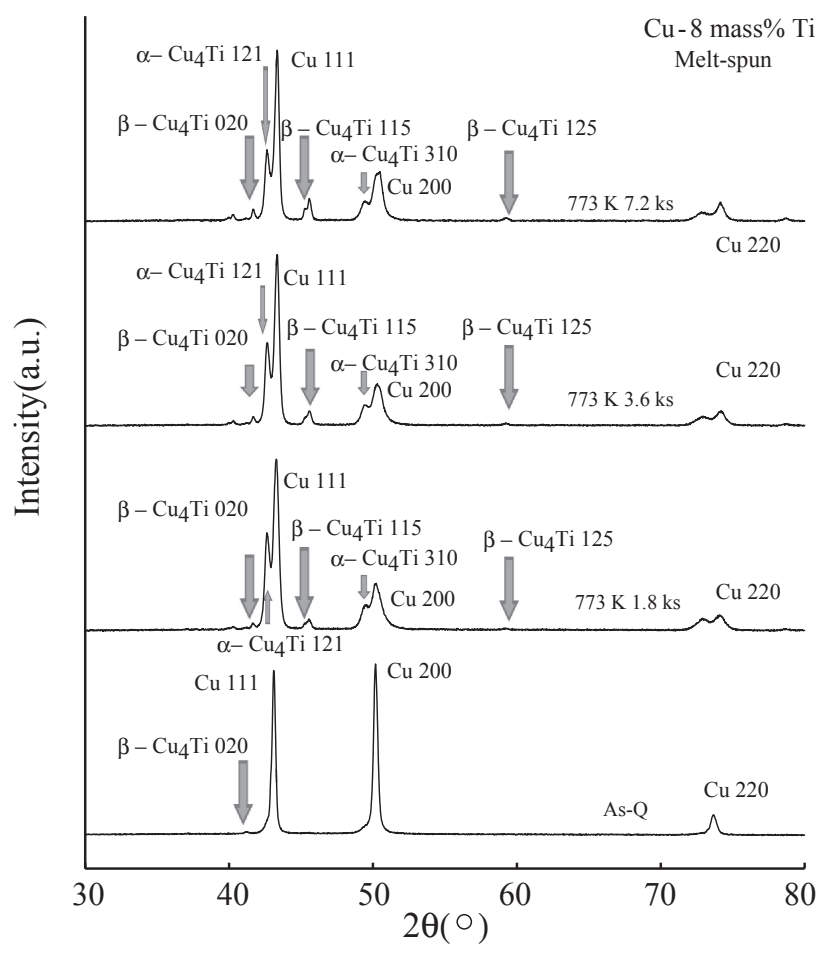

Fig. 15 XRD spectra of the melt-spun $\mathrm{Cu}-8$ mass\% Ti alloy samples aged at $773 \mathrm{~K}$ for 0 (As-Q), 1.8, 3.6, and $7.2 \mathrm{ks}$.

Furthermore, based on the XRD, BF TEM, and SADP results, it was demonstrated that melt-spun $\mathrm{Cu}-6$ and 7 mass \% Ti alloys undergo spinodal decomposition upon aging at $673 \mathrm{~K}$. In this study, however, the presence of superlattice reflections has not yet been investigated.

For the samples possessing a Ti content of 8 mass $\%$, small amounts of the stable $\beta-\mathrm{Cu}_{4} \mathrm{Ti}$ and metastable $\alpha-\mathrm{Cu}_{4} \mathrm{Ti}$ phases were detected upon rapid cooling. No growth of the stable $\beta-\mathrm{Cu}_{4} \mathrm{Ti}$ phase was observed, however, because the annealing temperature of $673 \mathrm{~K}$ and annealing time of up to $7.2 \mathrm{ks}$ were insufficient for the growth of this phase, which is mainly formed at high temperatures exceeding $773 \mathrm{~K}$. Actually, the stable $\beta$ - $\mathrm{Cu}_{4}$ Ti phase was easily detected at an aging temperature of $773 \mathrm{~K}$. In contrast, the formation of the metastable $\alpha-\mathrm{Cu}_{4} \mathrm{Ti}$ phase is presumably promoted during annealing at $673 \mathrm{~K}$. However, both the stable and metastable phases were simultaneously detected after annealing at $773 \mathrm{~K}$.

\section{REFERENCES}

1) J.A. Cornie, A. Datta and W.A. Soffa: Metall. Trans. 4 (1973) 727-733.

2) D.E. Laughlin and J.W. Cahn: Metall. Trans. 5 (1974) 972-974

3) D.E. Laughlin and J.W. Cahn: Acta Metall. 23 (1975) 329-339.

4) A. Datta and W.A. Soffa: Acta Metall. 24 (1976) 987-1001.

5) C.G. Woychik, R.J. Rioja, T.B. Massalski and D.E. Laughlin: Metall. Trans. A 16 (1985) 1353-1354.

6) C. Borchers: Philos. Mag. A 79 (1999) 537-547.

7) R.J. Price and A. Kelly: Acta Metall. 11 (1963) 915-922.

8) P. Wilkes: Acta Metall. 16 (1968) 153-158.

9) P.J. Rioja and D.E. Laughlin: Acta Metall. 28 (1980) 1301-1313.

10) S. Nagarjuna, K. Balasubramanian and D.S. Sarma: J. Mater. Sci. 34 (1999) 2929-2942.

11) S. Suzuki, K. Hirabayashi, H. Shibata, K. Mimura, M. Isshiki and Y.
Waseda: Scr. Mater. 48 (2003) 431-435.

12) W.A. Soffa and D.E. Laughlin: Prog. Mater. Sci. 49 (2004) 347-366.

13) J. Ikeda, S. Semboshi, A. Iwase, W. Gao and A. Sugawara: Mater. Trans. 56 (2015) 297-302.

14) S. Kasap and P. Capper: Springer Handbook of Electronic and Photonic Materials, 2nd ed., (Springer, Cham, Switzerland, 2017) pp. 26-27.

15) G.T. Meaden: Electrical Resistance of Metals, (Plenum Press, New York, USA, 1965) p. 112.

16) S. Nagarjuna, K. Balasubramanian and D.S. Sarma: Mater. Sci. Eng. A 225 (1997) 118-124.

17) S. Semboshi and T.J. Konno: J. Mater. Res. 23 (2008) 473-477.

18) K. Saito and T. Tsujimoto: J. Japan Inst. Metals 35 (1971) 764-769.

19) T. Tsujimoto, K. Saito and K. Hashimoto: J. Japan Inst. Metals 37 (1973) 61-67.

20) T. Tsujimoto, K. Hashimoto and K. Saito: J. Japan Inst. Metals 37 (1973) 67-72.

21) T. Tsujimoto and K. Saito: J. Japan Inst. Metals 37 (1973) 173-178.

22) S. Ikeno, S. Saji and S. Hori: J. Japan Inst. Metals 38 (1974) 11861191.

23) T. Tsujimoto: J. Japan Inst. Metals 39 (1975) 285-292.

24) A. Datta: PhD thesis, University of Pittsburgh, (1975).

25) S. Saji, S. Ikeno and S. Hori: J. Japan Inst. Metals 42 (1978) 63-68.

26) K.E. Biehl and R. Wagner: Proceedings of an International Conference on Solid-Solid phase Transformations, (Metallurgical Society of AIME, Pennylsvania, USA, 1982) p. 185.

27) S. Semboshi, T. Nishida and H. Numakura: Mater. Sci. Eng. A 517 (2009) 105-113.

28) I.S. Batra, G.K. Dey, U.D. Kulkarni and S. Banerjee: Mater. Sci. Eng. A 360 (2003) 220-227.

29) C. Borchers: Philos. Mag. A 79 (1999) 537-547.

30) C. Suryanarayana: Non-equilibrium Processing of Materials, (Pergamon Press, Oxford, UK, 1992).

31) P. Duwez: Trans. Am. Soc. Met. 60 (1967) 607-633.

32) L. Schultz: Mater. Sci. Eng. 97 (1988) 15-23.

33) C. Suryanarayana: Prog. Mater. Sci. 46 (2001) 1-184.

34) C. Suryanarayana and A. Inoue: Bulk Metallic Glasses, (CRC Press, Boca Raton, USA, 2011) pp. 145-186.

$35)$ D. Shechtman, I. Blech, D. Gratias and J.W. Cahn: Phys. Rev. Lett. 53 (1984) 1951-1953.

36) R.J. Schaefer: Scr. Metall. 20 (1986) 1187-1192.

37) E. Huttunen-Saarivirta: J. Alloys Compd. 363 (2004) 154-178.

38) F. Turquier, V.D. Cojocaru, M. Stir, R. Nicula and E. Burkel: J. NonCryst. Solids 353 (2007) 3417-3420.

39) S. Xi, K. Zuo, X. Li, G. Ran and J. Zhou: Acta Mater. 56 (2008) 60506060 .

40) R.S. Lei, M.P. Wang, Z. Li, H.G. Wei, W.C. Yang, Y.L. Jia and S. Gong: Mater. Sci. Eng. A 528 (2011) 4475-4481.

41) S. Mula, H. Bahmanpour, S. Mal, P.C. Kang, M. Atwater, W. Jian, R.O. Scattergood and C.C. Koch: Mater. Sci. Eng. A 539 (2012) 330336.

42) C. Suryanarayana: Mechanical Alloying and Milling, (Marcel Dekker, New York, USA, 2004) p. 166.

43) A. Bell and H.A. Davies: Mater. Sci. Eng. A 226-228 (1997) 10391041.

44) F. Findik: J. Mater. Sci. Lett. 12 (1993) 338-342.

45) J.-C. Zhao and M.R. Notis: Acta Mater. 46 (1998) 4203-4218.

46) J.Y. Brun, S.J. Hamar-Thibault and C.H. Allibert: Z. Metallk. 74 (1983) 525-529.

47) H. Miyake, A. Furusawa, T. Ariyasu and A. Okada: Imono 66 (1994) 734-738.

48) S. Saji, S. Ikeno and S. Hori: J. Japan Inst. Metals 42 (1978) 63-68.

49) F. Izumi and K. Momma: Solid State Phenom. 130 (2007) 15-20.

50) V. Daniel and H. Lipson: Proc. R. Soc. Lond. A 181 (1943) 368-378.

51) V. Ganesan and K.S. Raghavan: J. Mater. Sci. Lett. 15 (1996) 14711474.

52) L.D. Wang, C.L. Chen, M.K. Kang and Y.H. Wei: Scr. Mater. 42 (2000) $725-730$.

53) S. Semboshi, M. Ishikuro, S. Sato, K. Wagatsuma and T. Takasugi: Mater. Charact. 82 (2013) 23-31. 